\title{
Seroprevalence of Toxoplasma gondii in hunted wild boars (Sus scrofa) from southeastern France
}

\author{
Cédric Roqueplo ${ }^{1}$, Radu Blaga ${ }^{2}$, Jean-Lou Mariée ${ }^{1,3}$, Isabelle Vallée $^{2}$ and Bernard Davoust ${ }^{1,3}$ \\ ${ }^{1}$ French Forces Medical Service Working Group on Animal Epidemiology, Toulon, France; \\ ${ }^{2}$ Animal Health Laboratory, Université Paris-Est, Anses, École Nationale Vétérinaire, Institut National de la Recherche \\ Agronomique, Maisons-Alfort, France; \\ ${ }^{3}$ Research Unit of Emerging Infectious and Tropical Diseases, IHU Méditerranée Infection, Aix-Marseille Université, Marseille, \\ France
}

\begin{abstract}
Toxoplasma gondii (Nicolle et Manceaux, 1908) is an obligate intracellular, parasitic protozoan within the phylum Apicomplexa that causes toxoplasmosis in mammalian hosts (including humans) and birds. Since meat of wild boar, Sus scrofa (Linnaeus), has been demonstrated to be a potential source of human infection, a careful evaluation of the prevalence of infection with $T$. gondii in hunted animals is needed to protect public health. In the Var area in southeastern France, we performed a spatio-temporal survey in order to investigate the prevalence of IgG antibodies in wild boars shot by hunters in the Canjuers military camp during two subsequent hunting seasons. Of 841 wild boars screened, antibodies $(\operatorname{IgG})$ to $T$. gondii (modified agglutination test, cut-off $1: 6$ ) were found in $141(16.8 \%)$ muscle extract samples. A significant association $(\mathrm{p}<0.001)$ was found between positivity and age, but not gender, and hunting districts. The results obtained indicate that consumption of raw or undercooked meat from wild boars carries an important risk of infection with $T$. gondii. Wild boars may be considered as a bioindicator of parasite circulation in this ecosystem.
\end{abstract}

Keywords: toxoplasmosis, epidemiology, agglutination test, wildlife, seroprevalence

Toxoplasmosis, the most common parasitic zoonosis worldwide, is caused by the intracellular protozoan Toxoplasma gondii (Nicolle et Manceaux, 1908). The parasite infects most warm-blooded animals, including humans. Wild and domestic felids are the definitive hosts, excreting oocysts in faeces. Human toxoplasmosis is the most common parasitic zoonosis in the European Union ( 0.56 cases per 100,000 inhabitants) (European Food Safety Authority 2012). Data provided by the French National Reference Centre for Toxoplasmosis indicate that the number of congenital toxoplasmosis diagnosed every year in France is over 150 (2011, $\mathrm{n}=186 ; 2012, \mathrm{n}=204)$.

In addition to transplacental transmission, other routes of infection include undercooked meat consumption from intermediate hosts containing tissue cysts or water contaminated with oocysts. Among intermediate hosts, wild boars, Sus scrofa (Linnaeus), are commonly infected with T. gondii (see Bengis et al. 2004). Wild boars are widely distributed and this is also one of the most popular game animals in Europe. Over the last decades, wild boar populations in Europe have increased, impacting agriculture, livestock and biodiversity.

In France, we have observed a constant and significant increase for twenty years, especially in the south (Hars and
Rossi 2010). However, information on the recent prevalence of infection with $T$. gondii in hunted wild boar is limited, particularly in southeastern France, and almost non-existent for military camps. There are many military camps spread over throughout the France with a total area of $2,500 \mathrm{~km}^{2}$. The military camps offer particularly favourable conditions for the proliferation of wild boar (tranquility, large areas). Military hunting societies regulate animal numbers and the hunted animals are usually directly consumed by hunters and their families.

Wild game meat consumption has been highlighted as an emerging risk factor for infection with $T$. gondii in humans (Kijlstra and Jongert 2008), and the European Food Safety Authority has recommended the surveillance and monitoring of toxoplasmosis in humans, animals and foodstuffs. A careful evaluation of the prevalence of infection with $T$. gondii in hunted animals is needed to protect public health, especially since the percentage of seropositive people is decreasing, thus increasing the risk that people will first be exposed to the parasite as adults, which is a particular risk for pregnant women as it may lead to infection of the foetus in utero (Pappas et al. 2009, Torgerson and Mastroiacovo 2013, Tourdjman et al. 2015). The aim of the present study was to estimate the seroprevalence of infec- 
Table 1. Risk factors associated with positivity to Toxoplasma gondii (Nicolle et Manceaux, 1908) in hunted wild boar, Sus scrofa (Linnaeus).

\begin{tabular}{lccccc}
\hline Variables & $\begin{array}{c}\text { Positive animals No./ } \\
\text { Animal tested (\%) }\end{array}$ & $\begin{array}{c}95 \% \\
\text { confidence } \\
\text { interval }\end{array}$ & p-value & $\begin{array}{c}\text { Odds } \\
\text { ratio }\end{array}$ & $\begin{array}{c}95 \% \\
\text { confidence } \\
\text { interval }\end{array}$ \\
\hline Age group & & & & & \\
$\quad$ 6 months & $7 / 101(6.9 \%)$ & $2.8-13.8$ & - & - & - \\
$\quad$ 6-12 months & $46 / 234(19.7 \%)$ & $14.8-25.3$ & 0.0003 & 0.3 & $0.1-0.7$ \\
$\quad>12$ months & $88 / 506(17.4 \%)$ & $14.2-21.0$ & 0.03 & 0.4 & $0.2-0.9$ \\
Gender & & & & & \\
$\quad$ Male & $73 / 494(14.8 \%)$ & $11.8-18.3$ & 0.06 & 0.7 & $0.5-1.0$ \\
$\quad$ Female & $68 / 347(19.6 \%)$ & $15.6-24.2$ & - & - & - \\
Hunting seasons & & & & & \\
$\quad 2011$ & $68 / 305(22.3 \%)$ & $17.8-27.5$ & 0.001 & 1.8 & $1.3-2.6$ \\
$\quad 2012$ & $73 / 536(13.6 \%)$ & $10.9-16.9$ & - & - & - \\
Hunting districts & & & & & - \\
$\quad$ South & $65 / 382(17.0 \%)$ & $13.5-21.2$ & - & - & - \\
$\quad$ Middle & $39 / 263(14.8 \%)$ & $10.8-19.7$ & 0.4 & 1.2 & $0.7-1.8$ \\
$\quad$ North & $37 / 196(18.9 \%)$ & $13.6-25.1$ & 0.5 & 0.8 & $0.6-1.4$ \\
\hline
\end{tabular}

tion with $T$. gondii among wild boars in the military camp at Canjuers (southeastern France).

The study was carried out in the military camp at Canjuers, in the north of the Var region, southeastern France $\left(43^{\circ} 38^{\prime} 49^{\prime \prime} \mathrm{N}\right.$; $\left.06^{\circ} 27^{\prime} 56^{\prime \prime} \mathrm{E}\right)$. Canjuers camp is the largest firing range in Western Europe. The camp is located on the karstic massif of the Southern Pre-Alps, at an average altitude of 900 meters, dominated to the East by the mountain of Lachens, by the West by the Margès, and delimited to the north by the River Verdon. The Artuby, a tributary of the Verdon, circumscribes an enclave in the centre-North limited most often by gorges difficult to cross. The $350 \mathrm{~km}^{2}$ camp is a natural reserve for wild flora and fauna. It is mainly composed of moors and paths $(55 \%)$, woods (39\%) and arable land (6\%). The dominant tree species are Quercus pubescens, Pinus sylvestris, Fagus sylvatica, and Abies alba, interspersed with species such as Sorbus spp., Acer spp., Genista cinerea. It should be noted, on the southern of the camp, Quercus ilex lift with clear forests of Pinus halepensis and some disseminated Pinus pinaster. Wild boar, roe deer, Capreolus capreolus (Linnaeus) and red fox, Vulpes vulpes (Linnaeus), are the primary breeding wild mammals.

Muscle tissue samples (diaphragm and masseter; individual samples of about $100 \mathrm{~g}$ ) from 841 wild boars shot by hunters in the Canjuers camp during two subsequent hunting seasons (2011 and 2012) were collected, primarly for detection of Trichinella spp. Data from each wild boar (location, gender, weight) were recorded by hunters. The animal weights ranged from $10 \mathrm{~kg}$ to $120 \mathrm{~kg}$ (median: $45 \mathrm{~kg}$ ). Age estimation methods are usually based on the study of tooth development and most of these methods require laboratory procedures (Goncalves et al. 2016). The determination of exact ages by hunters in the field was not possible. In the present study, animal age was estimated based both on body weight and on fur colour. Wild boars were distributed into three age groups: piglets ( $\leq 6$ months), yearlings (red fur) (6-12 months), and subadults or adults ( $>12$ months).

The muscles were kept in a cryovial at $-20^{\circ} \mathrm{C}$ until the analyses were performed in the laboratory UMR BIPAR at Maisons-Alfort. Specifically, $100 \mathrm{~g}$ of mixed diaphragm and masseter muscles was frozen overnight at $-20^{\circ} \mathrm{C}$ in a plastic bag. After thawing at room temperature, the muscle fluid was collected with a pipette into a microtube and centrifuged $15 \mathrm{~min}$ at 4,000 rpm $(1,800 \mathrm{~g})$. The supernatant was collected and transferred into a new microtube.

The modified agglutination test (MAT) for the detection of $T$. gondii-specific IgG antibody was performed on meat extract using an antigen prepared from tachyzoites of the RH strain. The antigen was prepared according to the protocol of Desmonts and Remington (1980). On the microplate, a positive reaction is observed when the agglutination covers the entire surface of the well, a negative reaction when the antigen is sedimented at the bottom of the cup, and questionable reaction when agglutination covers only $50 \%$ of the surface, the drop off window. A dilution of $1: 6$ was used as a positive cut-off for epidemiological studies, in accordance with our observations and different studies (Djokic et al. 2016, Opsteegh et al. 2016).

The results were analysed by $2 \times \mathrm{K}$ contingency tables of exposure variables. The outcome variable was positivity to $T$. gondii and the independent variables were: age, gender, hunting seasons and hunting districts. Odds ratios, $95 \%$ confidence interval (CI) and p values were calculated separately for each variable using the Epi Info Software (v5.01, CDC Atlanta, USA). The Chi-square test was used to evaluate associations $(\alpha=5 \%)$. The differences were considered statistically significant when $\mathrm{p} \leq 0.05$.

One hundred forty-one of $841 \quad(16.8 \%, 95 \% \mathrm{CI}$ : $14.3-19.5 \%$ ) samples were found to be positive for antibodies against $T$. gondii, with a statistical difference $(\mathrm{p}=0.0003)$ between piglets $(6.9 \%, 95 \% \mathrm{CI}: 2.8-13.8)$ and yearlings (19.7\%, 95\% CI: 14.8-25.3), and between piglets and adults $(17.4 \%, 95 \% \mathrm{CI}: 14.2-21)(\mathrm{p}=0.03)$ (Table 1$)$. A statistically significant difference was also found between hunting seasons $(\mathrm{p}=0.001)$, with prevalence ranging from $13.6 \%$ to $22.3 \%$ (Table 1 ), whereas the wild boar population is homogeneous for age and sex among the two hunting seasons. Statistically significant differences were not observed between prevalence of $T$. gondii and gender or hunting district (Table 1). 
According to the hunting office of the French Ministry of Environment, Energy and Sea, the wild boar population is estimated between 1.8 and 2 million in France, and there were approximately between 450,000 and 500,000 wild boars killed by hunting during each investigated seasons. Knowledge about $T$. gondii infection in wild boar hunted in France is scarce. In previous studies conducted during the hunting season 2003-2004 in 21 French departments (Beral et al. 2012) and during the hunting seasons 2002-2008 in two distinct regions of France (Champagne-Ardenne and Corsica) (Richomme et al. 2009), antibodies to T. gondii were found in 23\% (216/938) and 18\% (26/148) of hunted wild boars, respectively. In our study, prevalence observed in wild boars $(16.8 \% ; 141 / 841)$ is similar to recent data from the Netherlands $(24.4 \%$; 237/973), Estonia (24\%; 113/471) (Jokelainen et al. 2015), Italy (14\%; 56/400) and Portugal (21\%; 20/97) (Opsteegh et al. 2011, Ranucci et al. 2013a, Coelho et al. 2014). In the Czech Republic and in Poland, Račka et al. (2015) and Witkowski et al. (2015) found higher values, i.e. prevalnce of $40.0 \%(260 / 656)$ and $37.6 \%$ (138/367), respectively.

However, many factors could influence these results (variable densities of wildcats, environmental oocyst contamination and moderate winter temperatures). Data obtained in individual studies can also vary due to the different sampling procedures, different diagnostic methods used and the choice of the cut-off value. The accuracy of meat extracts instead of serum in surveys prevalence of T. gondii is almost controversial (Wallander et al. 2015). Comparison of serum and meat juice for detection of antibodies against Toxoplasma gondii in hunted wild boars and comparison with data from other studies performed on blood samples should be made with precaution (Ranucci et al. 2013b). Also, by focusing on high titres $(\geq 1: 24)$, only $6.5 \%(55 / 841)$ of wild boars in our study are positive. This result is significantly different $(p<0.0001)$ from results obtained (with the same cut-off value) in previous studies performed in France (Richomme et al. 2009, Beral et al. 2012).

The modified agglutination test was used in the present stdy for the detection of $T$. gondii-specific IgG antibody. Among all serological tests available, the MAT is considered to be the most reliable for detecting antibodies to T. gondii in animals, especially in latently infected animals (Dubey 2010). In the present study, the $16.8 \%$ prevalence of $T$. gondii in wild boars was related to age. This is consistent with previous studies. The antibodies persist after infection and older animals would be expected to have higher seroprevalences than younger animals due to their greater opportunity to be exposed to the parasite.

Prevalence varied between hunting seasons. This could perhaps reflect variable contamination with oocysts in the environment. This reinforces the hypothesis that environmental oocyst contamination fluctuates, at least locally. The even distribution of positive animals across hunting districts shows that $T$. gondii is endemic, common and likely sustained by homogeneous infection pressure in the Canjuers camp. Wild boars may become infected by ingesting food or water contaminated with cat faeces, or by eating infected rodents or other raw meat. No wildcats, $\mathrm{Fe}$ lis silvestris (Schreber), or domestic/feral cats, Felis catus (Linnaeus), were observed in the Canjuers camp, but there are villages in the area surrounding the military camp, with domestic cats as everywhere in France. Small rodents as the wood mouse (Apodemus sylvaticus Linnaeus) are known to be abundant in the camp.

The wild boars examined in the present study were all hunted and presumably used for human consumption. No clinical signs of toxoplasmosis were reported in the wild boars of our study and all were apparently healthy. However, seropositivity has been shown to correlate well with chronic infection and infective cysts have been isolated in wild boars with MAT titres as low as 1: 6 (Richomme et al. 2009). The chronic infections were subclinical and meat inspection does not attempt to detect $T$. gondii, as this is not mandatory.

This study is to our knowledge the first carried out in a military camp in France. Our results suggest that a substantial proportion of wild boars that were hunted in the Canjuers camp carried infectious tissue cysts. Wild boars may represent a potential zoonotic risk for infection with T. gondii in humans if meat or meat products are consumed raw or undercooked. Further studies need to be conducted as the isolation of strains of $T$. gondii, which could provide valuable information about the biodiversity in a military camp.

Acknowledgements. We thank Société de chasse militaire de Canjuers, France for its support during the field work. We also thank C. Perret for processing the samples.

\section{REFERENCES}

Bengis R., Leighton F., Fisher J., Artois M., Morner T., TATE C. 2004: The role of wildlife in emerging and re-emerging zoonoses. Rev. Sci. Tec. 23: 497-511.

Beral M., Rossi S., Aubert D., Gasqui P., Terrier M.E., Klein F., Villena I., Abrial D., Gilot-Fromont E., Richomme C., Hars J., Jourdain E. 2012: Environmental factors associated with the seroprevalence of Toxoplasma gondii in wild boars (Sus scrofa), France. Ecohealth 9: 303-309.

Coelho C., Vieira-Pinto M., Faria A.S., Vale-Gonçalves H., Veloso O., Paiva-Cardoso M.D., Mesquita J.R., Lopes A.P. 2014: Serological evidence of Toxoplasma gondii in hunted wild boar from Portugal. Vet. Parasitol. 202: 310-312.
Desmonts G., Remington J.S. 1980: Direct agglutination test for diagnosis of Toxoplasma infection: method for increasing sensitivity and specificity. J. Clin. Microbiol. 11: 562-568.

Djokic V., Blaga R., Aubert D., Durand B., Perret C., Geers R., Ducry T., Vallee I., Duurkovic Djakovic O., Mzabi A., Villena I., Boireau P. 2016: Toxoplasma gondii infection in pork produced in France. Parasitology 143: 557-567.

Dubey J.P. 2010: Toxoplasmosis of Animals and Humans. Second Edition. CRC Press, Boca Raton Florida, 313 pp.

European Food Safety Authority 2012: Scientific of EFSA and ECDC: The European Union summary report on trends and sources of zoonoses, zoonotic agents and food-borne outbreaks in 2010. EFSA Journal 10: 2597. 
Goncalves P., Risco D., Fernández-Llario P., Barquero-Pérez O., Serrano E., Hermoso-de-Mendoza J., MaTEOS C. 2016: A new method for ageing wild boar using dental measures. Ecol. Indicat. 62: 328-332.

Hars J., Rossi S. 2010: Évaluation des risques sanitaires liés à l'augmentation des effectifs de sangliers en France. Faune Sauvage 288 : $23-28$

Jokelainen P., Velström K., Lassen B. 2015: Seroprevalence of Toxoplasma gondii in free ranging wild boars hunted for human consumption in Estonia. Acta Vet. Scand. 57: 42

Kijlstra A., Jongert E. 2008: Control of the risk of human toxoplasmosis transmitted by meat. Int. J. Parasitol. 38: 1359-1370.

Opsteegh M., Schares G., Blaga R., van der Giessen J. on BEHALF OF THE CONSORTIUM 2016: Experimental studies of of Toxoplasma gondii in the main livestock species (GP/EFSA BIOHAZ/2013/01) Final report. EFSA supporting publication 2016: EN-995, Parma, 161 pp.

Opsteegh M., Swart A., Fonville M., Dekkers L., Van der Giessen J. 2011: Age-related Toxoplasma gondii seroprevalence in Dutch wild boar inconsistent with lifelong persistence of antibodies. PLoS ONE 6: e16240.

Pappas G., Roussos N., Falagas M.E. 2009: Toxoplasmosis snapshots: global status of Toxoplasma gondii seroprevalence and implications for pregnancy and congenital toxoplasmosis. Int. J. Parasitol. 39: 1385-1394

RaČKa K., BÁRTová E., Budíková M., VodrážKa P. 2015: Survey of Toxoplasma gondii antibodies in meat juice of wild boar (Sus scrofa) in several districts of Czech Republic. Ann. Agric. Environ. Med. 22: 231-235.

Received 15 September 2016
Ranucci D., Veronesi F., Di Matteo I., Branciari R., MiRaglia D., Marini C., Fioretti D.P. 2013b: Comparison of serum and meat juice for detection of anti-Toxoplasma gondii antibodies in hunted wild boars (Sus scrofa). In: C. Boiti, A. Ferlazzo, A. Gaiti and A. Pugliese (Eds.), Trends in Veterinary Sciences. Springer-Verlag, Berlin Heidelberg, pp. 79-83.

Ranucci D., Veronesi F., Moretti A., Branciari R., Miraglia D., Manfredi M.T., Piergili Fioretti D. 2013a: Seroprevalence of Toxoplasma gondii in wild boars (Sus scrofa) from Central Italy. Parasite 20: 48

Richomme C., Aubert D., Gilot-Fromont E., Ajzenberg D., Mercier A., Ducrot C., Ferté H., Delorme D., Villena I. 2009: Genetic characterization of Toxoplasma gondii from wild boar (Sus scrofa) in France. Vet. Parasitol. 164: 296-300.

Torgerson P.R., Mastroiacovo P. 2013: The global burden of congenital toxoplasmosis: a systematic review. Bull. WHO 91: 501-508.

Tourdjman M., Tchéandjieu C., De Valk H., Goulet V., Le Strat Y. 2015: Toxoplasmose chez les femmes enceintes en France: évolution de la séroprévalence et des facteurs associés entre 1995 et 2010, à partir des enquêtes nationales périnatales. Bull. Epidémiol. Hebd. 15-16: 264-272.

Wallander C., Frössling J., VÅgsholm I., Burrells A., LUNDÉN A. 2015: "Meat Juice" is not a homogeneous serological matrix. Foodborne Pathog. Dis. 12: 280-288.

Witkowski L., Czopowicz M., Nagy D.A., Potarniche A.V., Aoanei M.A., Imomov N., Mickiewicz M., Welz M., Szalus-Jordanow O., KabA J. 2015: Seroprevalence of Toxoplasma gondii in wild boars, red deer and roe deer in Poland. Parasite 22: 17.

Cite this article as: Roqueplo C., Blaga R., Marié J.-L., Vallée I., Davoust B. 2017: Seroprevalence of Toxoplasma gondii in hunted wild boars (Sus scrofa) from southeastern France. Folia Parasitol. 64: 003. 